Issued by Sandia National Laboratories, operated for the United States Department of Energy by Sandia Corporation.

NOTICE: This report was prepared as an account of work sponsored by an agency of the United States Government. Neither the United States Government, nor any agency thereof, nor any of their employees, nor any of their contractors, subcontractors, or their employees, make any warranty, express or implied, or assume any legal liability or responsibility for the accuracy, completeness, or usefulness of any information, apparatus, product, or process disclosed, or represent that its use would not infringe privately owned rights. Reference herein to any specific commercial product, process, or service by trade name, trademark, manufacturer, or otherwise, does not necessarily constitute or imply its endorsement, recommendation, or favoring by the United States Government, any agency thereof, or any of their contractors or subcontractors. The views and opinions expressed herein do not necessarily state or reflect those of the United States Government, any agency thereof, or any of their contractors.

Printed in the United States of America. This report has been reproduced directly from the best available copy.

Available to DOE and DOE contractors from

Office of Scientific and Technical Information

P.O. Box 62

Oak Ridge, TN 37831

Prices available from (703) 605-6000

Web site: http://www.ntis.gov/ordering.htm

Available to the public from

National Technical Information Service

U.S. Department of Commerce

5285 Port Royal Rd

Springfield, VA 22161

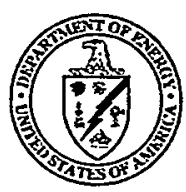




\section{DISCLAIMER}

Portions of this document may be illegible in electronic image products. Images are produced from the best available original document. 
SAND99-3191

Unlimited Release

Printed January 2000

\title{
Composite Wire Plasma Formation and Evolution
}

\author{
Rick B. Spielman \\ Z-Pinch Physics and Power Flow Department \\ Sandia National Laboratories \\ P.O. Box 5800 \\ Albuquerque, NM 87185-1194
}

\begin{abstract}
The detailed understanding of the formation and evolution of plasma from rapidly heated metallic wires is a long-standing challenge in the field of plasma physics and in exploding wire engineering. This physical process is made even more complicated if the wire material is composed of a number of individual layers. We have successfully developed both optical and $\mathrm{x}$-ray backlighting diagnostics. In particular, the $\mathrm{x}$-ray backlighting technique has demonstrated the capability for quantitative determination of the plasma density over a wide range of densities.

This diagnostic capability shows that the process of plasma formation is composed of two separate phases: first, current is passed through a cold wire and the wire is heated ohmically, and, second, the heated wire evolves gases that break down and forms a low-density plasma surrounding the wire.
\end{abstract}




\section{Contents}

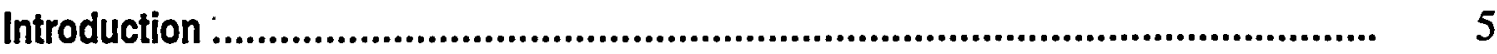

Description of LDRD Effort ...........................................................................

Progress Report on Tungsten and Aluminum Wire Explosions .................................. 5

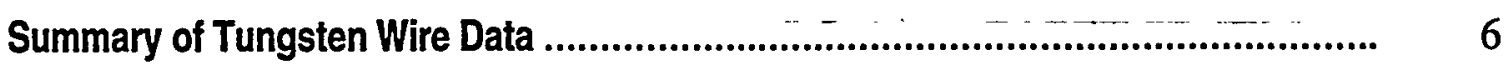

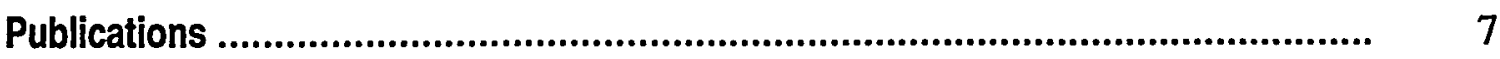

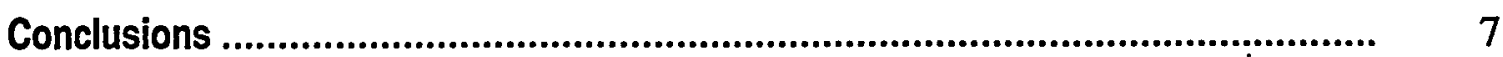




\section{Introduction}

The detailed understanding of the formation and evolution of plasmas from rapidly heated metallic wires (essentially a fusing action) is a long-standing challenge in the field of plasma physics and in exploding wire engineering. This physical process is made even more complicated if the wire material is a composite rather than a single element. It is critical to understand the essential physics in order to begin the process of modeling and prediction.

The expansion of wires in arrays is a key part of understanding the past success of wire array implosions on the $\mathbf{Z}$ accelerator at Sandia National Laboratories. Improvements in the performance of wire array loads on $\mathrm{Z}$ and future, larger, generators are predicated on improved understanding of the fundamental physics of wire initiation.

This LDRD was intended primarily to develop the experimental and diagnostic techniques needed to study the formation and evolution of such plasmas. These diagnostics included the possibility of optical and/or x-ray backlighting. Researchers at Cornell University successfully developed both optical and x-ray backlighting diagnostics. In particular, the X-ray backlighting technique has demonstrated the capability for quantitative determination of the plasma density over a wide range of densities.

As part of the deliverable for this LDRD we have identified the processes that are involved in wire initiation and are applying that knowledge to experiments on $\mathrm{Z}$.

\section{Description of LDRD Effort}

\section{Diagnostics}

LDRD resources were used to develop two key diagnostics and to apply them to the exploding wire problem. A $\mathrm{x}$-ray radiographic source based on the molybdenum $\mathrm{x}$ pinch was refined and used for a number of these experiments. A new laser was brought on line and is now being used to conduct shadowgraphy, Schlieren, and interferometry of exploding wires. All of the experimental work for this LDRD was conducted at Cornell University.

\section{Prepulse pulser}

Cornell built a pulser, which produces a current pulse having a 350-ns rise time and a 4.5-kA amplitude current. This pulser nearly duplicates the prepulse current seen on the $Z$ accelerator at Sandia National Laboratories.

\section{Progress Report on Tungsten and Aluminum Wire Explosions}

Graduate student Dan Sinars, technician Todd Blanchard, and Dr. John Greenley all of Cornell University have completed the setup of a separate wire pulser to drive an array of 1-4 wires. This pulser is capable of delivering a current waveform that is independent of the X-pinch backlighter driver, and can be independently adjusted in timing and amplitude to mock up prepulse conditions on $\mathrm{Z}$ or Saturn. The initial configuration drives up to $4 \mathrm{kA}$ in a 100-ns nearly-linear rise time. In order to time the $\mathrm{x}$-pinch backlighter 
pulses accurately, we needed to trigger this pulser off the intermediate store waveform of the $\mathrm{x}$ pinch, which required a pulser with very short throughput trigger delay. A thyratron-switched system was tried first, but Cornell ended up with a gas switch triggered by a PT55, which is satisfactory. A low-inductance cable feedthrough was constructed to get the pulse to the wires, which are mounted on a fixture positioned suitably with respect to the $\mathrm{x}$ pinches.

Dr. John Greenley was very concerned about being able to mock up not just the prepulse current per wire, but also the global magnetic field of the array on $\mathrm{Z}$ which, as has often been pointed out, sweeps coronal plasma off the wires instead of pinching onto the wire core as with a single wire. To model this, the wire(s) driven by the new wire pulser are located near one of the legs of the current return for the X-pinch, and we can vary the current and position of that leg with respect to the wires to apply a suitable "global" magnetic field at the wires.

Cornell researchers now have several good images of both $\mathrm{W}$ and $\mathrm{Al}$ wires under Saturn and Z-like prepulse conditions. With 7.5- $\mu \mathrm{m}$ diameter $\mathrm{W}$ wire, they see no significant expansion of the core and no coronal plasma, with a current of $1 \mathrm{kA}$ at $50 \mathrm{~ns}$. This is not surprising given their previous results at higher currents. It is going to take a much heftier prepulse and much longer expansion time to really spread out $W$ wires significantly. Cornell will try to do that in FY00.

With $\mathrm{Al}$ wires, the situation is quite different. With a current rising to $1 \mathrm{kA}$ in $100 \mathrm{~ns}$ like Saturn prepulse, $13-\mu \mathrm{m}$ diameter $\mathrm{Al}$ wires are significantly expanded. It appears that almost all the mass is still in the core visible on these images, which has expanded to about $100-\mu \mathrm{m}$ diameter. This is still a long way from "merging" of most of the mass, and there is already a disturbing variety of behavior visible: on one shot with two wires, one can see that each wire has rather uniformly expanded along its length, but one wire is about $100-\mu \mathrm{m}$ diameter with a diffuse profile, while the other is only $60-\mu \mathrm{m}$ diameter with a very sharp edge to the profile (shot 1329). On shot 1326, both of these profiles occur at different places along ONE wire, with an absolutely sharp axial boundary between them. Cornell is working on quantifying the mass line density for these $\mathrm{Al}$ wire images.

Bruce Kusse and technician Frank LaBonte of Cornell University are working on the setup of the new YAG laser for complementary shadowgraphy, schlieren, interferometry and polarimetry. The laser is now set up and operating in the second harmonic, and triggering synchronization with the pinch drivers is being worked out. A new graduate student has joined the project this fall, and Prof. Kusse has several undergraduate students and a M.Eng. student involved as well.

\section{Summary of Tungsten Wire Data}

\section{Single wires.}

1. For thick $\mathrm{W}$ wires (40- $\mu \mathrm{m}$ diameter) and a peak current level up to $100 \mathrm{kA}$ at a typical time of $50 \mathrm{~ns}$ into the current pulse, there is no obvious difference in total mass of evaporated wire material in explosions of preheated wires and wires without preheating. Only a small fraction of the wire mass $(5-10 \%)$ is evaporated into the coronal plasma. The detectable outer radius is uneven (it looks like it was $\mathrm{m}=0$ unstable), but reaches out as far as $500 \mu \mathrm{m}$. 
2. For $20-\mu \mathrm{m}$ diameter $\mathrm{W}$ wires, the fraction of evaporated material increases to 30 $50 \%$, and this does depend on wire preheating. The preheated wire has the greater amount of coronal material and expands more.

3. With thin $W$ wires (7.5 - $10 \mu \mathrm{m}$ diameters) the amount of evaporated material reaches $70-90 \%$ of the initial wire mass by $40-60 \mathrm{~ns}$ after the start of the current pulse, but there is still a dense core at that time. The residual core diameter is just a few times the initial wire diameter. The coronal plasma has more of the initial wire mass, and expands considerably faster, when the wire is preheated. [Cornell believes that the residual "dirt" on the wires forms a plasma around the $\mathrm{W}$ at relatively low temperature, stealing current from the metal when the wire is not preheated, thereby reducing the power delivered to the $\mathrm{W}$ in the early stages of wire explosion.].

4. The thin wires also develop "gaps" by $50 \mathrm{~ns}$ or so. Axial movement of the corona plasma was observed, especially around core breaks, as evidenced by the linear density of the coronal plasma appearing to be as much as twice initial linear density of the wire on the two sides of the gaps. [Note: the backlighter diagnostic does not distinguish between $\mathrm{W}$ vapor and ionized $\mathrm{W}$. Thus, this summary refers to evaporated material and coronal plasma interchangeably.]

II. Wire arrays.

1. In the early stages (30-40 ns) of wire explosion with as many as 8 and as few as 2 wires, with 15 - $50 \mathrm{kA}$ peak current per wire, depending upon the number of wires, evaporated wire material concentrates mainly around the dense cores.

2. In later stages the corona plasma spreads between wires and forms a dense plasma channel in the middle of the wire array. (These were all linear arrays.)

3. When wires are preheated the coronal plasma formation process goes faster, as above, and coronal plasma densities are about twice as much as without preheating at the same time in a similar current pulse with the same diameter wires. However, the amount of evaporated material at a specific time certainly depends on current pulse shape and amplitude.

4. Under the same conditions (amplitude of the current through the array, with 100$120 \mathrm{kA}$ total current) the portion of the initial wire mass in the coronal plasma: a) increases as the wire diameter decreases (20\% for. a $4 \times 13.3 \mu \mathrm{m}$ array and $40 \%$ for a $4 \times 7.5 \mu \mathrm{m}$ array). b) decreases with an increasing number of wires in wire array ( $40 \%$ for a $4 \times 7.5 \mu \mathrm{m}$ array and $26 \%$ for an $8 \times 7.5 \mu \mathrm{m}$ array).

\section{Publications}

David B. Sinars, Tatiana A. Shelkovenko, Sergei A. Pikuz, John B. Greenly and David A. Hammer, "Exploding Aluminum Wire Plasma Formation", accepted for publication in Applied Physics Letters.

\section{Conclusions}

The goals of the work defined by the LDRD were substantially met or exceeded. These were:

1. Develop two key diagnostics and to apply them to the exploding wire problem. A xray radiographic source based on the molybdenum $x$ pinch was refined and used for $a$ 
number of these experiments. A new laser was brought on line and is now being used to conduct shadowgraphy, Schlieren, and interferometry of exploding wires.

2. Build a pulser that produces a current pulse having a $350-\mathrm{ns}$ rise time and a $4.5-\mathrm{kA}$ amplitude current. This pulser nearly duplicates the prepulse current seen on the $Z$ accelerator at Sandia National Laboratories.

3. Obtain preliminary results on the expansion of tungsten and aluminum wires.

4. Obtain preliminary results on the expansion of composite wires. 


\section{Distribution:}

1 MS 1190 J. P. Quintenz, 1600

1 MS 1194 D. H. McDaniel, 1640

5 MS 1194 R. B. Spielman, 1644

1 MS 1194 M. R. Douglas, 1644

1 MS 1194 C. Deeney, 1644

1 MS 1191 M. K. Matzen, 1670

1 MS 1193 J. L. Porter, 1673

1 MS 1193 M. E. Cuneo, 1673

1 MS 1186 T. A. Mehlhorn, 1674

1 MS $1196 \quad$ R. J. Leeper, 1677

1 MS $1194 \quad$ G. A: Chandler, 1677

1 MS 0839 G. Yonas, 16000

1 MS 9018 Central Technical Files, 8940-2

2 MS 0899 Technical Library, 4916

1 MS 0612 Review and Approval Desk, 4912 For DOE/OSTI 